\title{
Ratiometric measurements of adiponectin by mass spectrometry in bottlenose dolphins (Tursiops truncatus) with iron overload reveal an association with insulin resistance and glucagon
}

\author{
Benjamin A. Neely ${ }^{1}$, Kevin P. Carlin ${ }^{2}$, John M. Arthur ${ }^{1,3}$, Wayne E. McFee ${ }^{4}$ and Michael G. Janech ${ }^{1 *}$ \\ ${ }^{1}$ Department of Medicine, Division of Nephrology, Medical University of South Carolina, Charleston, SC, USA \\ ${ }^{2}$ Translational Medicine and Research Program, National Marine Mammal Foundation, San Diego, CA, USA \\ ${ }^{3}$ Ralph H. Johnson Veterans Affairs Medical Center, Charleston, SC, USA \\ ${ }^{4}$ NOAA's Ocean Service, National Centers for Coastal Ocean Science, Center for Coastal Environmental Health and Biomolecular Research, Charleston, SC, USA
}

\section{Edited by:}

Stephanie Venn-Watson, National Marine Mammal Foundation, USA

Reviewed by:

Andrzej Bartke, Southern Illinois University School of Medicine, USA Jennifer L. Estall, Institut de Recherches Cliniques de Montreal, Canada

\section{*Correspondence:}

Michael G. Janech, Department of Medicine, Division of Nephrology, Medical University of South Carolina 829 Clinical Sciences Building, 96 Jonathan Lucas Street, Charleston, SC 29425, USA

e-mail: janechmg@musc.edu
High molecular weight (HMW) adiponectin levels are reduced in humans with type 2 diabetes and insulin resistance. Similar to humans with insulin resistance, managed bottlenose dolphins (Tursiops truncatus) diagnosed with hemochromatosis (iron overload) have higher levels of $2 \mathrm{~h}$ post-prandial plasma insulin than healthy controls. A parallel reaction monitoring assay for dolphin serum adiponectin was developed based on tryptic peptides identified by mass spectrometry. Using identified post-translational modifications, a differential measurement was constructed. Total and unmodified adiponectin levels were measured in sera from dolphins with $(n=4)$ and without $(n=5)$ iron overload. This measurement yielded total adiponectin levels as well as site specific percent unmodified adiponectin that may inversely correlate with HMW adiponectin. Differences in insulin levels between iron overload cases and controls were observed $2 \mathrm{~h}$ post-prandial, but not during the fasting state. Thus, post-prandial as well as fasting serum adiponectin levels were measured to determine whether adiponectin and insulin would follow similar patterns. There was no difference in total adiponectin or percent unmodified adiponectin from case or control fasting animals. There was no difference in post-prandial total adiponectin levels between case and control dolphins (mean \pm SD) at $763 \pm 298$ and $727 \pm 291 \mathrm{pmol} / \mathrm{ml}$, respectively $(p=0.91$ ); however, percent unmodified adiponectin was significantly higher in post-prandial cases compared to controls $(30.0 \pm 6.3$ versus $17.0 \pm 6.6 \%$, respectively; $p=0.016)$. Interestingly, both total and percent unmodified adiponectin were correlated with glucagon levels in controls $(r=0.999, p<0.001)$, but not in cases, which is possibly a reflection of insulin resistance. Although total adiponectin levels were not significantly different, the elevated percent unmodified adiponectin follows a trend similar to HMW adiponectin reported for humans with metabolic disorders.

Keywords: parallel reaction monitoring, marine mammal, assay, hemochromatosis, liver, diabetes

\section{INTRODUCTION}

Managed dolphins have higher serum ferritin levels, total serum iron levels, percent transferrin saturation, and total iron binding capacity compared to free-ranging dolphins (1). Managed dolphins are also susceptible to hemochromatosis (iron overload) where iron deposition in Kupffer cells is a prevalent diagnostic feature (2). While the cause of iron accumulation or iron overload is not known, elevated post-prandial insulin levels in dolphins were associated with excessive hepatic iron deposition (3). Humans with elevated iron stores but without hemochromatosis can have clinical laboratory values consistent with metabolic syndrome and insulin resistance (4), and hepatic iron overload is associated with insulin resistance regardless of the extent of liver damage (5).

Adiponectin is an adipokine primarily secreted by adipocytes and is considered an insulin-sensitizing hormone. Low circulating levels of adiponectin are associated with hyperinsulinemia (6), high liver lipid content, and obesity (7). Recently, iron was implicated in the direct negative regulation of adiponectin production by adipocytes which resulted in insulin resistance in mice (8) suggesting that the relationship between iron, adiponectin, and insulin sensitivity are tightly intertwined. Previous findings of elevated $2 \mathrm{~h}$ post-prandial serum insulin and glucagon levels in dolphins with hemochromatosis compared to controls, suggest that dolphins with iron overload may be unable to properly regulate insulin levels (3); however it is not known whether this observed postprandial insulin and glucagon response is correlated with total serum adiponectin.

Reports of blood adiponectin levels in marine mammals are limited to a single species, Northern elephant seals (Mirounga angustirostris), and were measured in pups using a canine ELISA assay $(9,10)$. Interestingly, the mean levels reported were one to two orders of magnitude lower than mean levels reported for 
dogs (11-13), suggesting that marine mammals may have low circulating adiponectin levels, Northern elephant seals have low adiponectin levels, or that the ELISA assay utilized had limited cross-reactivity to elephant seal adiponectin. To assess true crossreactivity of an antibody, a fully recombinant adiponectin protein is required, which is not commercially available for marine mammals. Cross-reactivity concerns can be avoided by utilizing an alternative mass spectrometry-based direct detection approach, parallel reaction monitoring [PRM; $(14,15)]$. This method is similar to selected reaction monitoring (SRM) with the exception that all product ions from a collision induced dissociation reaction are monitored and available for extraction (16).

Adiponectin exists as multimers, commonly referred to as high and low molecular weight (HMW and LMW). Multimerization is largely governed by post-translational modifications (PTMs) within the collagenous domain of the protein and glycosylation following lysine hydroxylation is reported to be key in the formation of multimers as well as the ability to properly phosphorylate AMP-kinase in liver tissue (17). Because HMW adiponectin is best associated with diabetes and metabolic syndrome $(18,19)$ and because glycosylation of lysine is an important modification that drives intracellular AMP-kinase signaling, a new method is presented to provide a differential measurement of tryptic adiponectin peptides that could reflect some degree of lysine modification to serve as a proxy of adiponectin modification and possibly multimerization. This method relies on the differential measurement of total adiponectin and unmodified Lys75 adiponectin peptides to investigate whether degree of modification is associated with outcome data. Therefore, it was hypothesized that the fraction of total adiponectin that is unmodified at a known lysine (Lys75) would be elevated in iron overload dolphins at the $2 \mathrm{~h}$ post-prandial time point compared to controls. Additionally, it was hypothesized that $2 \mathrm{~h}$ post-prandial levels of total adiponectin would be lower compared to a control group of dolphins.

\section{MATERIALS AND METHODS \\ PRM METHOD DEVELOPMENT SERUM}

A single dolphin serum was used for PRM assay development, taken from a $2.44 \mathrm{~m}$ long female bottlenose dolphin (SC-0145). The dolphin was captured, sampled, and released on June 26, 2001 during a NOAA sponsored rescue and relocation operation of two dolphins located in a fresh water reservoir near Charleston, South Carolina. Both dolphins had moved into the freshwater reservoir on June 6,2001 . The sample was stored at $-80^{\circ} \mathrm{C}$. Before processing further, the serum was thawed at $37^{\circ} \mathrm{C}$ for $2-5 \mathrm{~min}$, before being aliquoted into $110 \mu \mathrm{l}$ aliquots which were frozen at $-80^{\circ} \mathrm{C}$. These aliquots were used fresh daily by thawing at $37^{\circ} \mathrm{C}$ for $1 \mathrm{~min}$ and mixed briefly by vortexing before use.

\section{IRON OVERLOAD CASE-CONTROL STUDY POPULATION}

The study population consisted of nine bottlenose dolphins at the U.S. Navy Marine Mammal Program (MMP), including six females and three males with ages ranging from 8 to 48 years. The study included four dolphins with iron overload (cases) and five controls. Iron overload cases in this study were previously reported to have chronically elevated serum aminotransferases, specifically alanine aminotransferase (ALT) and aspartate aminotransferase
(AST), as well as elevated serum iron (20). These four case animals had since undergone phlebotomy treatments in order to manage iron overload, and diagnoses of iron overload have been confirmed by live liver biopsies in three of the four animals (21). Control animals had normal blood values throughout the year before sample collection, specifically iron, ALT, and AST, based upon published reference ranges for healthy bottlenose dolphins (22). Of these control animals, one female surrogate was lactating and nursing a calf and another was in the early stage of pregnancy during the $2 \mathrm{~h}$ post-prandial phase.

\section{IRON OVERLOAD CASE-CONTROL STUDY POPULATION DIET}

Marine Mammal Program dolphins were fed high-quality, frozenthawed fish and mollusks, including capelin (Mallotus villosus), herring (Clupea harengus), mackerel (Scomber scombrus), and squid (Loligo brevis). They received daily vitamin supplementation that did not include iron, as well as periodic anti-parasitic medications for prophylaxis. Proximate analysis was used to assess nutrient concentration in fish fed during the study period. Crude protein concentration was determined at Michelson Laboratories, Inc. (Commerce, CA, USA) using standard methods (23). Fed protein was calculated using the protein concentration reported by Michelson Labs along with daily food intake and animal weight. Measurements for age, weight, and fed protein were based on collection dates from $2 \mathrm{~h}$ post-prandial samples. If no length data was available on the weight date, the nearest length measurement was used. BMI was calculated using the standard human equation: weight per square length (kilogram per square meter).

\section{IRON OVERLOAD CASE-CONTROL STUDY SAMPLE COLLECTION}

Marine Mammal Program dolphins are trained to voluntarily allow collection of blood from the ventral fluke veins. Blood was collected in BD Vacutainer (Rutherford, NJ, USA) blood collection tubes using 20- or 21-gage, $1.5^{\prime \prime}$ needles. Blood was collected in ethylenediaminetetraacetic acid (EDTA), serum separator tubes (SST), and red top tubes (no additive). One vial each of serum and EDTA whole blood were submitted to Quest Diagnostic Laboratories (San Diego, CA, USA) or the Naval Medical Center (San Diego, CA, USA) for analysis of serum chemistry and complete blood count (CBC). Remaining blood was centrifuged at $3000 \mathrm{rpm}$ for $10 \mathrm{~min}$ and separated prior to archiving. Serum and plasma samples were stored frozen at $-80^{\circ} \mathrm{C}$ until analysis. EDTA plasma samples were processed and frozen within $30 \mathrm{~min}$ of blood collection. Plasma was analyzed for insulin and glucagon at Esoterix Inc., Laboratory Services (Calabasas Hills, CA, USA). The tests for insulin and glucagon have not been validated in dolphins. Fasting and $2 \mathrm{~h}$ post-prandial samples were 132-706 days (489 days on average) apart.

\section{SERUM HEMATOLOGICAL ANALYSIS AND CALCULATIONS}

Serum biochemistry and CBC analyses were performed at the Naval Medical Center using a Cobas 8000 Modular Analyzer Series (Roche Diagnostics, Indianapolis, IN, USA) and Beckman Coulter LH755 (Beckman Coulter, Brea, CA, USA), respectively, as well as at Quest Diagnostics using a Coulter LH 750 (Beckman Coulter, Fullerton, CA, USA) and Olympus AU600 (Olympus America, Center Valley, PA, USA). Serum chemistry analyses included glucose, sodium, potassium, chloride, carbon dioxide, anion gap, 
creatinine, blood urea nitrogen (BUN), uric acid, total bilirubin, total protein, alkaline phosphatase (ALP), ALT, AST, lactate dehydrogenase (LDH), gamma-glutamyl transpeptidase (GGT), and iron. CBC analyses included total white blood cell count with differential, red blood cell count, hemoglobin, hematocrit, mean corpuscular volume, mean corpuscular hemoglobin, and mean corpuscular hemoglobin concentration (MCHC). EDTA plasma samples correlating to serum samples used were analyzed by Esoterix Inc., Laboratory Services for total insulin and glucagon. Insulin was measured by two-site manual immunochemiluminometric assay (ICMA). Glucagon was measured by radioimmunoassay (RIA) following addition of aprotinin injection (Trasylol ${ }^{\circledR}$, Bayer Pharmaceuticals Corporation, West Haven, CT, USA).

Homeostasis Model Assessment for Insulin Resistance (HOMA-IR) was calculated using a standard equation used in human endocrinology: [plasma insulin $(\mu \mathrm{IU} / \mathrm{ml}) \times$ serum glucose $(\mathrm{mg} / \mathrm{dl})] / 405$ (24). Erythrocyte sedimentation rates (ESR; 60-min) were analyzed in-house from EDTA whole blood using Fisherbrand Dispette $2{ }^{\circledR}$ (Fisher Scientific, Waltham, MA, USA), correlating with the Westergren method. Estimated glomerular filtration rate (eGFR) was calculated using a dolphin-specific equation based on serum creatinine (25).

\section{REAGENTS AND CHEMICALS}

All reagents were ACS grade or higher. Water and acetonitrile were LC-MS grade (Honeywell Burdick and Jackson, Morristown, NJ, USA). Solutions of ammonium bicarbonate, dithiothreitol (DTT), and iodoacetamide (IAA) were made fresh each day. Only Protein Lo-Bind (Eppendorf, Hamburg, Germany) microcentrifuge tubes were used to minimize protein and peptide adsorption.

\section{DEPLETED SERUM PREPARATION FOR TARGET PEPTIDE SELECTION}

To confirm target proteotypic adiponectin peptides, an aliquot of the "method development serum" was utilized. Protein concentrations were determined by the Bio-Rad Protein assay (Hercules, CA, USA) which is based on the Bradford method. A Multiple Affinity Removal System (MARS) Human 14 spin cartridge (Agilent Technologies, Santa Clara, CA, USA) was used to deplete $30 \mu \mathrm{l}$ of serum $(3 \times 10 \mu \mathrm{l})$ which depleted the sample from 1000 to $139 \mu \mathrm{g}$ protein. The resulting eluent was precipitated with acetone, then reconstituted in RapiGest SF Surfactant (Waters, Milford, MA, USA), reduced with $5 \mathrm{mM}$ DTT, alkylated with $15 \mathrm{mM}$ IAA, and digested overnight with Promega Gold trypsin (Promega, Madison, WI, USA) at an enzyme-to-protein ratio of 1:50 (w:w). The digest was halted with $0.1 \%$ formic acid $(\mathrm{v} / \mathrm{v})$ and the resulting peptides were desalted using a $30 \mathrm{mg}$ Strata-X $33 \mu$ polymeric reverse phase solid phase extraction column (Phenomenex, Torrance, CA, USA), washed with $1 \mathrm{ml} 5 \%$ acetonitrile in $0.1 \%$ formic acid, and eluted with $1 \mathrm{ml} 60 \%$ acetonitrile in $0.1 \%$ formic acid. The eluent was dried under vacuum with spinning followed by resuspension in mobile phase A (MPA) (98\% water, $2 \%$ acetonitrile, $0.1 \%$ formic acid) to a concentration of $0.25 \mu \mathrm{g} / \mu \mathrm{l}$ protein (as estimated by $\mathrm{Abs}_{280}$ ), and $10 \mu \mathrm{l}$ was injected onto the LC-MS/MS as described below.

\section{SYNTHETIC PEPTIDE STANDARDS}

The following peptides were synthesized by New England Peptide (Gardner, MA, USA) with isotopically labeled (“^”; ${ }^{13} \mathrm{C}$ and ${ }^{15} \mathrm{~N}$ ) c-terminus amino acids: IFYNQQSHYDGTTGK ${ }^{\wedge}$ (IFY) and GDTGETGVTGVEGPR ${ }^{\wedge}($ GDT). The manufacturer verified labeled peptide concentration by amino acid analysis of an aliquot made from $0.5 \mathrm{mg}$ of each standard, after which $100 \mu \mathrm{l}$ aliquots at approximately $200 \mu \mathrm{M}$ in $30 \%$ acetonitrile (v/v) $0.1 \%$ formic acid $(\mathrm{v} / \mathrm{v})$ were frozen at $-80^{\circ} \mathrm{C}$. For collision energy optimizations, external calibration curves, and sample analyses, fresh aliquots were used by first thawing at $37^{\circ} \mathrm{C}$ for $1 \mathrm{~min}$ and then diluted in $10 \%$ acetonitrile $(\mathrm{v} / \mathrm{v}) 0.1 \%$ formic acid $(\mathrm{v} / \mathrm{v})$ to achieve the desired concentration.

\section{PREPARATION OF TRYPTIC PEPTIDES FOR ANALYSIS}

Prior to digesting the samples, a protocol was optimized for digesting dolphin serum. The amount of serum, acid-cleavable detergent, trypsin, and different desalting elutions were evaluated to maximize assay sensitivity and eliminate sources of experimental error. The resulting protocol is as follows: frozen serum aliquots were thawed at $37^{\circ} \mathrm{C}$ for $1 \mathrm{~min}$ and vortexed for $5 \mathrm{~s}$. A $5 \mu \mathrm{l}$ aliquot of serum was transferred to a $1.5 \mathrm{ml}$ microcentrifuge tube, and $45 \mu \mathrm{l} 50 \mathrm{mM}$ ammonium bicarbonate (AmBic) was added. To this mixture, $50 \mu \mathrm{l}$ of $0.1 \%(\mathrm{w} / \mathrm{v})$ Progenta ${ }^{\mathrm{TM}}$ Anionic Acid Labile Surfactant II (AALS2; Progenta ${ }^{\mathrm{TM}}$ Protea Biosciences, Morgantown, $\mathrm{WV}$, USA) dissolved in $50 \mathrm{mM}$ AmBic was added and mixed by pipetting. To this mixture $11 \mu \mathrm{l}$ of $1 \mathrm{M}$ DTT (in $25 \mathrm{mM}$ AmBic) was added and incubated for $30 \mathrm{~min}$ at $60^{\circ} \mathrm{C}$. The reaction was allowed to cool $5 \mathrm{~min}$ before $12.5 \mu \mathrm{l}$ IAA (in $100 \mathrm{mM}$ AmBic) was added and incubated in the dark for $30 \mathrm{~min}$ at $37^{\circ} \mathrm{C}$. The reaction was brought to $200 \mu \mathrm{l}$ with $50 \mathrm{mM}$ AmBic before trypsin was added at an enzyme-to-protein ratio of 1:10 (w:w). Finally $100 \mu \mathrm{l}$ $100 \mathrm{mM}$ AmBic was added and the digest was incubated for $16 \mathrm{~h}$ at $37^{\circ} \mathrm{C}$ in the dark. After $16 \mathrm{~h}$, the digest was stopped with the addition of $350 \mu \mathrm{l} 1 \%$ formic acid (v/v), and left at room temperature for $30 \mathrm{~min}$ to allow for the AALS2 to be cleaved. Next, $300 \mu \mathrm{l}$ of $0.1 \%$ formic acid was added to bring the final volume to approximately $1 \mathrm{ml}$. Additionally, $30 \mu \mathrm{l}$ of a $100 \mathrm{fmol} / \mu \mathrm{l}$ internal standard (IS) mix comprised of the two isotopically labeled peptides in $10 \%$ acetonitrile $(\mathrm{v} / \mathrm{v})$ was added, which corresponded to $3000 \mathrm{fmol}$ of each IS. Following the manufacturer's protocol, the complete volume was loaded onto a methanol-conditioned $30 \mathrm{mg}$ Strata-X $33 \mu$ polymeric reverse phase solid phase extraction column (Phenomenex, Torrance, CA, USA) and washed three times with $0.1 \%$ formic acid followed by $5 \%$ acetonitrile $(\mathrm{v} / \mathrm{v})$ in $0.1 \%$ formic acid. The peptides were eluted using $1 \mathrm{ml}$ 15\% acetonitrile in $0.1 \%$ formic acid. The elution was frozen at $-80^{\circ} \mathrm{C}$, and dried under vacuum by speedvac. Next $100 \mu$ l of MPA ( $98 \%$ water, $2 \%$ acetonitrile, $0.1 \%$ formic acid) was added, the sample was vortexed $15 \mathrm{~min}$, centrifuged at $10,000 \times g$ for $5 \mathrm{~min}$, and the resulting supernatant was transferred to a clean $1.5 \mathrm{ml}$ microcentrifuge tube. At this stage, the sample protein concentration was approximately $7 \mu \mathrm{g} / \mu \mathrm{l}$ (as estimated by $\mathrm{Abs}_{280}$ ), therefore prior to injection, $25 \mu \mathrm{l}$ was diluted into $975 \mu \mathrm{l}$ of MPA, and was analyzed by LC-MS/MS.

\section{LC-MS/MS}

Prior to analysis by tandem mass spectrometry, the performance of the LC-MS/MS was confirmed using a standard tryptic digest of $\beta$-galactosidase by evaluating precursor retention times, and fragment ion areas. Tryptic peptides $(10 \mu \mathrm{l})$ were injected onto 
a $100 \mu \mathrm{m} \times 1 \mathrm{~cm} \mathrm{C18} \mathrm{(100 \AA} \mathrm{with} 5-\mathrm{mm}$ particles) trap column (Acclaim PepMap 100; Thermo Fisher Scientific), and separated on a $75 \mu \mathrm{m} \times 15 \mathrm{~cm} \mathrm{C18} \mathrm{(300 \AA} \mathrm{with} 3-\mu \mathrm{m}$ particles) analytical column (Acclaim PepMap 100; Thermo Fisher Scientific). Reverse phase separation at $300 \mathrm{nl} / \mathrm{min}$ was performed with a gradient of 3-30\% mobile phase B [95\% acetonitrile (v/v), 0.1\% formic acid $(\mathrm{v} / \mathrm{v})]$ over $12 \mathrm{~min}$ on a $2 \mathrm{D}+\mathrm{NanoLC}$ system (Eksigent, Dublin, CA, USA). The LC was interfaced to a TripleTOF 5600 System (AB Sciex, Foster City, CA, USA) with a nanospray source. Source temp was set at $120^{\circ} \mathrm{C}$, and source voltage was set at $2500 \mathrm{~V}$. The declustering potential was set at $110 \mathrm{~V}$. To identify target proteotypic peptides, the instrument was run in positive ion instrument dependent acquisition mode with precursor ion scans for $250 \mathrm{~ms}$ with up to 20 product ion scans of $50 \mathrm{~ms}$ if precursors were 300 $1250 \mathrm{~m} / \mathrm{z}$, exceeded $125 \mathrm{cps}$, and had a $2+$ to $5+$ charge state. For PRM experiments, the dominant charge state of each peptide was chosen and collision energies were optimized for each peptide. In one case the $2+$ precursor was used, GDT, while the $3+$ precursor was used for IFY. Collision energies were optimized for each peptide by monitoring the relative intensity of abundant fragment ions that had an $\mathrm{m} / \mathrm{z}$ greater than the precursor $\mathrm{m} / \mathrm{z}$. The value which yielded the highest fragment ion area was used, which typically was close to the CE predicted by the equation determined by Kuzyk et al. (26): $\mathrm{CE}=0.043 \times($ precursor ion $m / z)+2.25$. For PRM, the instrument was set in positive ion mode and collected TOF-MS data in a window of 450-1250 m/z for $150 \mathrm{~ms}$, followed by each parent ion MS/MS for $400 \mathrm{~ms}$, collecting data from 100 to $1600 \mathrm{~m} / z$. Due to the nature of the TripleTOF mass spectrometer, all ion pairs were monitored. The precursor masses were cycled such that the unlabeled peptide was collected, followed by the corresponding isotopically labeled peptide, before moving to the next peptide. For each peptide the three fragment ions with highest abundance were selected and used for PRM experiments (Figure S1 and Table S1 in Supplementary Material).

\section{PEPTIDE IDENTIFICATION}

For determination of target peptides, raw data generated by the AB Sciex 5600 were converted to a peak list using the AB Sciex MS Data Converter (v. 1.1 beta, July 2011). Protein identifications were made using Mascot (v. 2.3.02) searching against the Ensembl (release 64) turTru1 dolphin genome assembly protein database [16,598 sequences; (27)] and the common Repository of Adventitious Proteins database (cRAP; 2012.01.01; the Global Proteome Machine) using the following parameters: trypsin was selected as the enzyme and three missed cleavages were allowed; carbamidomethylation (Cys) was specified as a fixed modification; glucosylgalactosyl (Lys), oxidation (Met, Pro), and 2-succinyl (Cys) were specified as variable modifications; a precursor tolerance of $10 \mathrm{ppm}$ and fragment ion tolerance of $0.5 \mathrm{Da}$; instrument type was ESI-QUAD-TOF. The mass spectrometry proteomics data have been deposited to the ProteomeXchange Consortium (http://proteomecentral.proteomexchange.org) via the PRIDE partner repository (28) with the dataset identifier PXD000431.

\section{EXTERNAL CALIBRATION CURVES AND ADIPONECTIN MEASUREMENT}

An external calibration curve was constructed using a mix of both labeled peptides in a digestion matrix with a peptide concentration approximately the same as the test samples. This was accomplished by digesting and processing the "method development serum" sample using the optimized protocol. After SPE clean up, the digest was brought up in $100 \mu \mathrm{l} \mathrm{MPA}$, and $5 \mu \mathrm{l}$ of this was diluted into $175 \mu \mathrm{l} \mathrm{MPA}$ and $20 \mu \mathrm{l}$ of a $10 \times$ standard solution (for each calibration point) resulting in approximately $0.5 \mu \mathrm{g} / \mu \mathrm{l}$ protein digest. Twelve concentrations of labeled peptide were used from 0.005 to $10 \mathrm{fmol} / \mu \mathrm{l}$, and $10 \mu \mathrm{l}$ of each was injected onto the LC-MS/MS in triplicate and the instrument acquired data as described above. Quantitative measurements were calculated by using area under the curve for ion pairs using the built-in MQ4 algorithm in MultiQuant (v 2.0.2, AB Sciex). The following parameters were used for peak determination: 3.0 Gaussian smooth width, minimum peak width of three points, minimum peak height of 0.00 . Integration parameters were as follows: $40 \%$ noise, 2 min baseline subtraction window, four points peak splitting. Fragment ions were extracted from each MS/MS experiment using a predicted monoisotopic mass $\pm 0.05 \mathrm{~m} / \mathrm{z}$. Regression was performed using peak areas with a linear fit and a $1 / x$ weighting. There was a linear relationship of instrument response to analyte concentration from 0.05 to $100 \mathrm{fmol}$ for all peptides and relevant fragment ions (Figures S2S7 in Supplementary Material). Using the "best" ion pair for each peptide (IFY $\mathrm{y}^{2+}$ and GDT $\mathrm{y} 7$ ), there was no concentration that had relative standard deviations higher than $20 \%$; therefore experimental assay variability and limits of detection and quantification were determined within experimental analysis as opposed to using the external curve for such calculations. An experimental blank was processed during each digestion batch, which was $5 \mu \mathrm{l}$ phosphate buffered saline digested exactly the same as test samples, with $15 \mu \mathrm{g}$ trypsin used for digestion. This blank was used to calculate the limit of detection (LOD) and limit of quantification (LOQ) on the days of analysis. This was accomplished by measuring the standard deviation of triplicate blank area measurements and the following equations: $(m=$ slope of external calibration curve) $\mathrm{LOD}=3 \sigma / \mathrm{m} ; \mathrm{LOQ}=10 \sigma / \mathrm{m}$ (29). Additionally, one sample was digested in triplicate during each batch of digestion and was analyzed to determine experimental variability. Lastly, a composite serum sample was used as an in-house internal reference material to correct between experimental batches. The peak areas for the $y 13^{2+}$ ion of IFY and the $y 7$ ion of GDT of both the labeled and unlabeled peptides were extracted with MultiQuant and used to calculate the amount of adiponectin in samples. Experimental variability was calculated using experimental triplicates and was $<15 \%$ RSD (Table S3 in Supplementary Material). Daily LOD and LOQ were calculated for the assay and the serum measurements were more than two orders of magnitude above LOQ. Additionally, the IS area and the average analyte area were within one order of magnitude. Taken together, these parameters indicated the assay was performing with high sensitivity and precision. Lastly, the measurement of IFY was used to indicate total adiponectin and the measurement of GDT to indicate the amount of unmodified Lys75 adiponectin such that percent unmodified Lys75 adiponectin is: $(\mathrm{GDT} / \mathrm{IFY}) \times 100$.

\section{STATISTICS}

Wilcoxon rank-sum test was used to compare continuous variables between two groups with both SAS (v 9.1, SAS Incorporated) and 
MATLAB (R2013a; Mathworks), and since there were fewer than 10 individuals per category, the exact test was performed. Fisher's exact test was used to compare categorical factors. Pearson Product

Table 1 | Identified adiponectin peptides and their modifications.

\begin{tabular}{llcl}
\hline Position & Peptide sequence and modifications & $\begin{array}{l}\text { Ion } \\
\text { score }\end{array}$ & $\begin{array}{l}\text { Expect } \\
\text { value }\end{array}$ \\
\hline 57-90 & $\begin{array}{l}\text { DGSPGEKGEKGGPGFAGPKGDTGETGVT } \\
\text { GVEGPR }\end{array}$ & 70 & $1.3 \mathrm{E}-6$ \\
& 3 Glucosylgalactosyl (K); Oxidation (P) & & \\
64-90 & GEKGDPGFAGPKGDTGETGVTGVEGPR & 41 & $6.7 \mathrm{E}-4$ \\
& 2 Glucosylgalactosyl (K) & & \\
$76-90$ & GDTGETGVTGVEGPR & 110 & $2.6 \mathrm{E}-5$ \\
$91-98$ & GFPGIPGR & 30 & 0.002 \\
& 2 Oxidation (P) & 103 & $5.4 \mathrm{E}-10$ \\
$99-110$ & KGEPGESAYVYR & & \\
& Glucosylgalactosyl (K) & 62 & $4.2 \mathrm{E}-6$ \\
$111-120$ & SAFSVGLETR & 53 & $1.0 \mathrm{E}-5$ \\
$121-129$ & VTIPNVPIR & 75 & $1.1 \mathrm{E}-6$ \\
$133-147$ & IFYNQQSHYDGTTGK & 72 & $4.0 \mathrm{E}-7$ \\
$191-205$ & NVDQASGSVLLYLEK & &
\end{tabular}

Tryptic peptides from dolphin adiponectin were identified by tandem mass spectrometry followed by database searching using Mascot. Modified residues predicted by Mascot are in bold and underlined, with modifications indicated below each peptide sequence. Peptide position relative to the whole protein, Mascot ion scores, and statistical probability of the identity match being random (Expect Value) are presented.
Moment Correlation analysis was performed with SigmaPlot 11.0 (Systat Software).

\section{RESULTS \\ DEVELOPMENT OF ADIPONECTIN ASSAY}

In order to select proteotypic adiponectin peptides for quantification by PRM, digested endogenous dolphin adiponectin was analyzed by tandem mass spectrometry. Using a Tursiops truncatus protein database and by specifying known and predicted adiponectin modifications (30-36) nine peptides were identified for a total of $43 \%$ coverage of the 242 amino acid dolphin adiponectin (Ensemble ID ENSTTRP00000015964; Table 1). Three hydroxylated prolines (Pro60, Pro93, Pro96) and four glucosylgalactosyl lysines (Lys63, Lys66, Lys75, Lys99) in the collagenous domain were identified (Figure 1). There was no evidence of succination (Cys). From the list of identified peptides and corresponding predicted chemical properties (e.g., solubility) two target peptides were selected: IFYNQQSHYDGTTGK (IFY) and GDTGETGVTGVEGPR (GDT). Sample processing and instrument parameters were optimized to measure these two peptides in dolphin serum using PRM.

\section{IRON OVERLOAD CASE-CONTROL STUDY}

While comparisons are limited based upon the small sample size, there were no significant differences in gender, age, weight, length, BMI, or diet between the two groups (Table 2). Blood values were compared between cases and controls within the fasting and $2 \mathrm{~h}$ post-prandial sample sets (Table 3 ). Within the fasting samples, ALT and GGT were significantly higher in the iron overload group ( $p=0.0159$ and 0.0476 , respectively) while MCHC was significantly lower (Table S2 in Supplementary Material; $p=0.0317$ ) compared to controls. Iron was not significantly different, which was expected since the iron overload samples were taken postphlebotomy (21). Within the post-prandial set, ALT was also

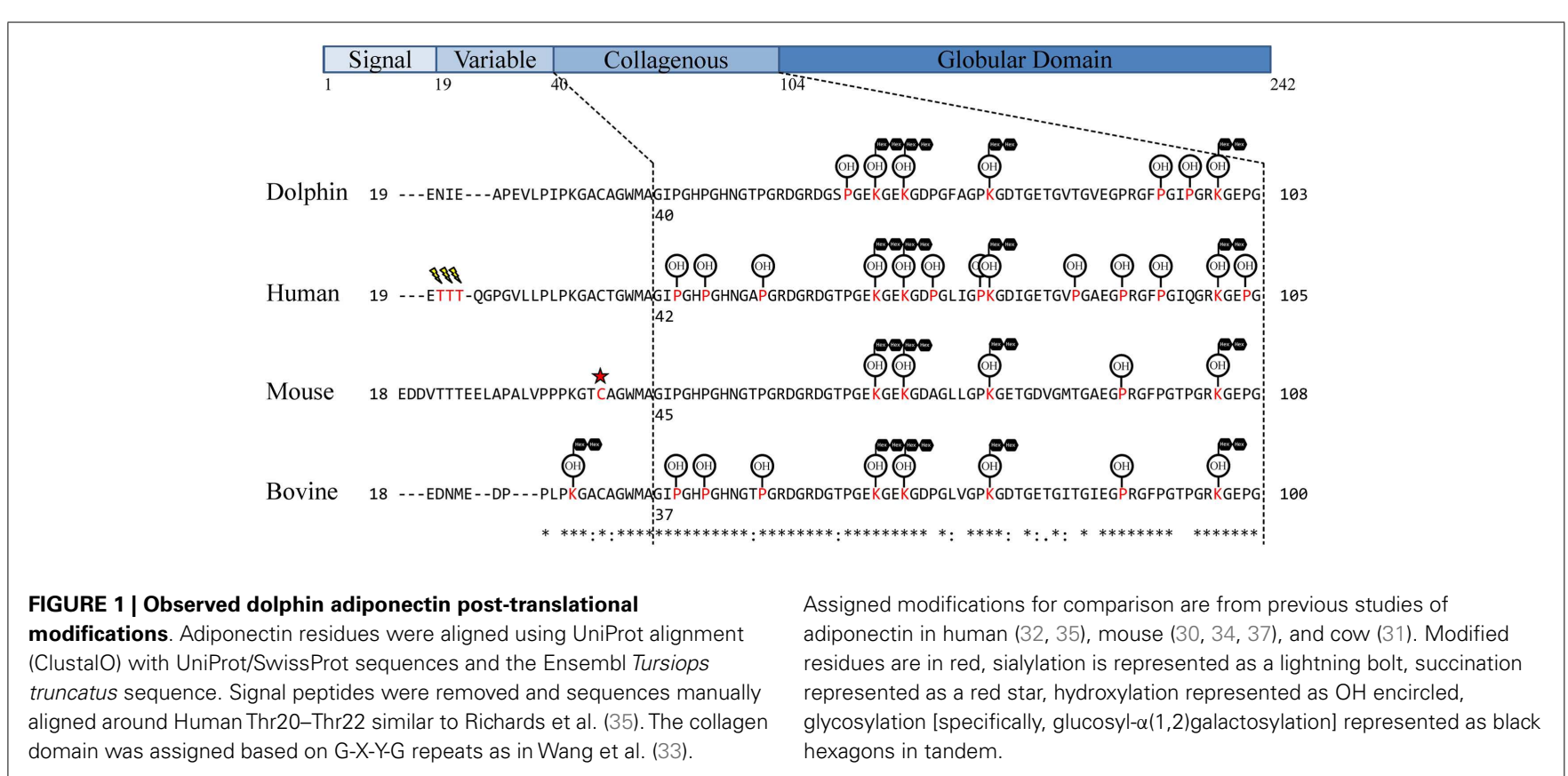


Table 2 | Study group characteristics table.

\begin{tabular}{|c|c|c|c|}
\hline Characteristic & Iron overload & Control & $p$-Value \\
\hline \multicolumn{4}{|l|}{ SEX, $N(\%)$} \\
\hline Female & $2(50 \%)$ & $4(80 \%)$ & 0.524 \\
\hline Male & $2(50 \%)$ & $1(20 \%)$ & \\
\hline \multicolumn{4}{|l|}{ AGE (years) } \\
\hline Mean \pm SD & $34.3 \pm 7.5$ & $26 \pm 15.2$ & 0.286 \\
\hline Median & 32.4 & 26.9 & \\
\hline Range & $27.5-44.8$ & $8-47.9$ & \\
\hline \multicolumn{4}{|l|}{ WEIGHT (kg) } \\
\hline Mean \pm SD & $200.3 \pm 45.3$ & $186.1 \pm 32.3$ & 0.730 \\
\hline Median & 196.8 & 172.3 & \\
\hline Range & $160-247.7$ & $147.7-223.2$ & \\
\hline \multicolumn{4}{|l|}{ LENGTH $(\mathrm{cm})$} \\
\hline Mean \pm SD & $261 \pm 20$ & $253 \pm 8$ & 0.857 \\
\hline Median & 260 & 255 & \\
\hline Range & $241-284$ & $242-264$ & \\
\hline \multicolumn{4}{|l|}{ BMI $\left(\mathrm{kg} / \mathrm{m}^{2}\right)$} \\
\hline Mean \pm SD & $29 \pm 2.4$ & $29 \pm 4.5$ & 0.556 \\
\hline Median & 29.1 & 26.5 & \\
\hline Range & $26.5-31.4$ & $25.2-36$ & \\
\hline \multicolumn{4}{|c|}{ FED PROTEIN $(\mathbf{g} / \mathbf{k g})$} \\
\hline Mean \pm SD & $6.3 \pm 1$ & $6.6 \pm 1.4$ & 0.556 \\
\hline Median & 6.4 & 6.8 & \\
\hline Range & $4.9-7.2$ & $5.1-8.4$ & \\
\hline
\end{tabular}

All data is temporally related to the $2 \mathrm{~h}$ post-prandial sample set, and dietary data is from the draw date's protein load. Comparisons between the groups were made using Fisher's exact test for categorical factors and Wilcoxon rank-sum test for continuous variables.

higher and MCHC (Table S2 in Supplementary Material) was lower in the iron overload group $(p=0.0159$ and 0.0159 , respectively) compared to controls. Additionally, total bilirubin, anion gap (Table S2 in Supplementary Material), insulin, and HOMAIR were higher in the iron overload group $(p=0.0476,0.0357$, 0.0159 , and 0.032 , respectively) compared to controls. Specifically, insulin was $39.0 \pm 18.8 \mu \mathrm{IU} / \mathrm{ml}$ and $7.7 \pm 5.8 \mu \mathrm{IU} / \mathrm{ml}$ and HOMA-IR scores were $10 \pm 5$ and $2 \pm 1$, for iron overload cases and controls, respectively.

Total (IFY) and percent unmodified Lys75 adiponectin (GDT) were compared between controls and iron overload cases within fasting or post-prandial samples (Figure 2). Total adiponectin was not different between the two groups either fasting or postprandial. The average total adiponectin $( \pm S D)$ in the fasting samples was $1233 \pm 597 \mathrm{pmol} / \mathrm{ml}$ and $1245 \pm 130 \mathrm{pmol} / \mathrm{ml}$ for control and iron overload subjects, respectively. The average total adiponectin in the post-prandial samples was $727 \pm 291 \mathrm{pmol} / \mathrm{ml}$ and $763 \pm 298 \mathrm{pmol} / \mathrm{ml}$ for control and iron overload subjects, respectively. Percent unmodified adiponectin was not different between the two groups within the fasting samples at $20.2 \pm 4.1$ and $21.7 \pm 6.9 \%$ in control and iron overload samples, respectively. Percent unmodified adiponectin was significantly higher in iron overload subjects within the post-prandial samples $(p=0.016)$ at $17.0 \pm 6.6$ and $30.0 \pm 6.3 \%$ in control and iron overload subjects, respectively. Using a threshold of greater than $23.1 \%$ unmodified adiponectin, these two groups were completely separated in the post-prandial samples.

Levels of total and percent unmodified adiponectin were also compared to evaluate gender differences. In the fasting sample set, total adiponectin in males was $1362 \pm 59 \mathrm{pmol} / \mathrm{ml}$ (with $26.7 \pm 2.8 \%$ unmodified) and in females was $1177 \pm 529 \mathrm{pmol} / \mathrm{ml}$ (with $18.0 \pm 3.2 \%$ unmodified). In the $2 \mathrm{~h}$ post-prandial samples, total adiponectin in males was $1023 \pm 194 \mathrm{pmol} / \mathrm{ml}$ (with $25.3 \pm 3.6 \%$ unmodified) and in females was $601 \pm 183$ (with $21.4 \pm 11.1 \%$ unmodified).

Correlations were evaluated between metabolic variables, total adiponectin, and percent unmodified adiponectin in the postprandial samples (Table 4). For the control group, total, and percent unmodified adiponectin were significantly positively correlated $(p<0.05)$ with each other. Both total and percent unmodified adiponectin were significantly positively correlated with glucagon levels $(\rho=0.934$ and 0.999 , respectively; $p<0.05$; Figure 3). Neither were significantly correlated to glucose, insulin levels, or HOMA-IR. Comparing the same variables in the iron overload subjects, there was no significant correlation. Specifically, the striking correlation of glucagon and percent unmodified adiponectin in the controls (Figure $\mathbf{3 A}$ ) was completely absent in the iron overload cases (Figure 3B).

\section{DISCUSSION ASSAY DEVELOPMENT FOR DOLPHIN ADIPONECTIN}

In this study tryptic peptides belonging to adiponectin from the bottlenose dolphin were identified using liquid chromatography tandem mass spectrometry. These peptides were used to develop a reaction monitoring assay to quantify adiponectin in dolphin serum. Since a high resolution mass spectrometer was used that did not isolate individual fragment ions in a distal quadrupole, this type of analysis has been termed PRM (16). Reaction monitoring is gaining popularity as a tool for estimating protein quantity using peptides derived from proteolytic digestion (14), with the added benefit that it can be multiplexed and provides a level of specificity through direct analyte detection that is not afforded by antibody-based techniques. As this study highlights, one of the more liberating aspects of reaction monitoring is the fact that it can be quickly adapted to measure clinically relevant proteins in nonmodel organisms if a protein sequence is known and proteolytic peptides can be detected. Moreover, this data demonstrates that a mid-abundance serum protein, adiponectin $(0.06 \%$ of total serum protein in the method development sample), can be quantified without depletion or enrichment prior to analysis. Quantifying proteins in this direct manner has been demonstrated before using SRM (38-40).

The range of total adiponectin concentrations in the study population was $383-1827 \mathrm{pmol} / \mathrm{ml}$, corresponding to $10-48 \mu \mathrm{g} / \mathrm{ml}$ adiponectin. This is within the reported range for humans (41), mice (42), dogs (43), and cows (44) (see Table S4 in Supplementary Material). In reference to reported adiponectin values from the elephant seal $(9,10)$, order Carnivora, the dolphin levels were approximately 20 - to 170 -fold higher, suggesting either a massive difference in the circulating level of adiponectin between marine mammals or a reflection of the assay utilized to measure 
Table 3 | Hematologic and serum biochemistry data of study group.

\begin{tabular}{|c|c|c|c|c|c|c|}
\hline & \multicolumn{3}{|c|}{$2 \mathrm{~h}$ post-prandial } & \multicolumn{3}{|c|}{ Fasting } \\
\hline & Iron overload & Control & $p$-Value & Iron overload & Control & $p$-Value \\
\hline HGB (g/dl) & $12.6 \pm 2.5$ & $12.9 \pm 0.8$ & 0.730 & $12.0 \pm 1.0$ & $13.0 \pm 0.8$ & 0.214 \\
\hline Platelets $\left(10^{3} / \mu \mathrm{l}\right)$ & $57.3 \pm 23.0$ & $78.2 \pm 18.5$ & 0.191 & $78.8 \pm 14.6$ & $104.0 \pm 36.1$ & 0.286 \\
\hline Eosinophils (cells/ $\mu l)$ & $746 \pm 266$ & $1025 \pm 900$ & 0.905 & $1024 \pm 638$ & $1218 \pm 365$ & 0.905 \\
\hline Protein (g/dl) & $7.0 \pm 0.4$ & $6.4 \pm 0.4$ & 0.079 & $7.3 \pm 0.2$ & $6.6 \pm 0.5$ & 0.056 \\
\hline Albumin (g/dl) & $4.2 \pm 1.9$ & $4.9 \pm 0.3$ & 0.960 & $5.0 \pm 0.8$ & $4.2 \pm 0.3$ & 0.214 \\
\hline Globulins (g/dl) & - & - & - & $2.9 \pm 0.1$ & $2.4 \pm 0.3$ & 0.095 \\
\hline ALP (U/I) & $290 \pm 152$ & $320 \pm 100$ & 0.730 & $259 \pm 134$ & $262 \pm 104$ & 0.905 \\
\hline LDH (U/I) & $476 \pm 106$ & $455 \pm 55$ & 1.000 & $462 \pm 147$ & $346 \pm 70$ & 0.214 \\
\hline AST (U/I) & $275 \pm 49$ & $190 \pm 111$ & 0.191 & $346 \pm 97$ & $229 \pm 100$ & 0.191 \\
\hline Cholesterol (mg/dl) & $234 \pm 92$ & $203 \pm 25$ & 1.000 & $245 \pm 71$ & $199 \pm 29$ & 0.286 \\
\hline Triglycerides (mg/dl) & $101 \pm 10$ & $101 \pm 36$ & 0.786 & $124 \pm 86$ & $71 \pm 18$ & 0.191 \\
\hline $\mathrm{Fe}(\mu \mathrm{g} / \mathrm{dl})$ & $205 \pm 65$ & $162 \pm 65$ & 0.413 & $210 \pm 85$ & $159 \pm 29$ & 0.516 \\
\hline $\mathrm{ESR}(\mathrm{mm} / \mathrm{h})$ & $8 \pm 11$ & $13 \pm 6$ & 0.413 & $15 \pm 21$ & $9 \pm 6$ & 0.849 \\
\hline eGFR $\left(\mathrm{ml} / \mathrm{min} / 2.78 \mathrm{~m}^{2}\right)$ & $217 \pm 30$ & $271 \pm 32$ & 0.087 & $199 \pm 8$ & $243 \pm 39$ & 0.119 \\
\hline Insulin $(\mu|\bigcup / m|)$ & $39 \pm 19$ & $8 \pm 6$ & $0.016^{*}$ & $14 \pm 12$ & $17 \pm 17$ & 0.849 \\
\hline Glucagon (pg/ml) & $155 \pm 54$ & $87 \pm 54$ & 0.286 & - & - & - \\
\hline HOMA-IR & $10 \pm 5$ & $2 \pm 1$ & $0.032 *$ & $4 \pm 4$ & $5 \pm 5$ & 0.730 \\
\hline
\end{tabular}

A Wilcoxon rank-sum test was used to compare blood chemistry values between groups, and significance indicated by "* if $p<0.05$. A complete table of hematologic and serum biochemistry values can be found in Table S2 in Supplementary Material.

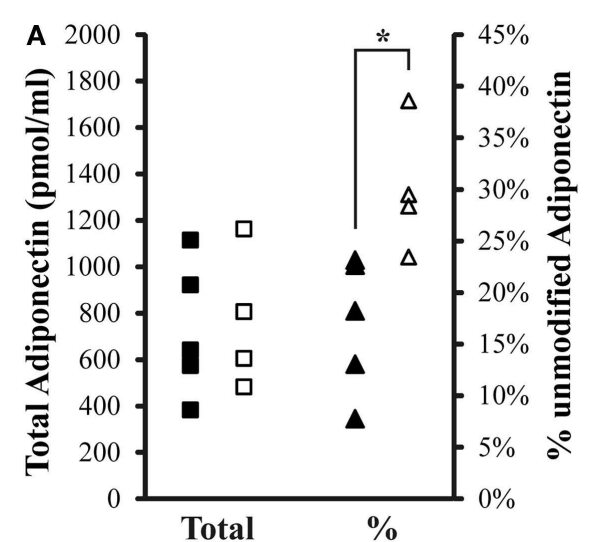

FIGURE 2 |Total and percent unmodified adiponectin levels in post-prandial and fasting samples. (A) Two hours post-prandial and (B) fasting sample sets. Squares are total adiponectin and triangles are

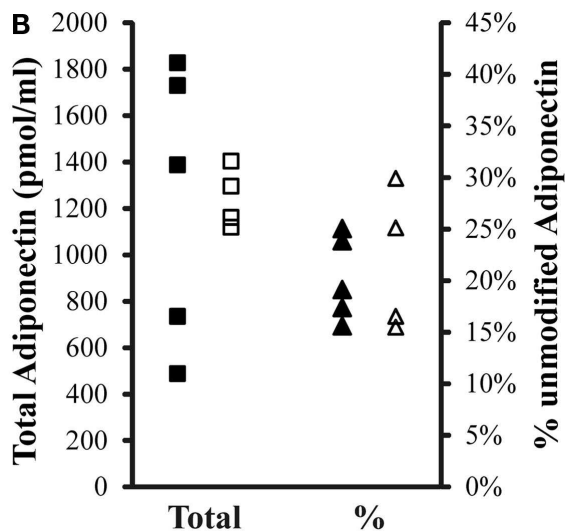

percent unmodified adiponectin. Solid symbols are controls and hollow symbols are iron overload cases. An "*" indicates significance difference $(p<0.05)$ when comparing the groups. adiponectin. Comparative generalizations made across mammals would be premature at this stage due to lack of standardization of assay methodology.

Adiponectin exists as a variety of multimers, dictated by PTMs in the collagenous domain. Oligomerization is key to directing the receptor-mediated biological activities of adiponectin.
For instance, monomeric adiponectin produced by recombinant bacterial systems does not form HMW multimers compared to adiponectin produced by mammalian expression systems, and thus does not repress serum glucose $(45,46)$. Further, the amount of HMW adiponectin (18-30+ protomers) but not total adiponectin correlates to improved insulin sensitivity in mice and 
Table 4 | Pearson product moment correlations $(\rho)$ of variables within groups in the $2 \mathrm{~h}$ post-prandial sample set.

\begin{tabular}{|c|c|c|c|c|c|}
\hline & Unmodified adiponectin (\%) & Glucose & Insulin & Glucagon & HOMA-IR \\
\hline \multicolumn{6}{|l|}{ CONTROL GROUP } \\
\hline \multirow[t]{2}{*}{ Total adiponectin } & $\rho=0.940$ & $\rho=0.160$ & $\rho=0.257$ & $\rho=0.934$ & $\rho=0.260$ \\
\hline & $p=0.0174^{*}$ & $p=0.797$ & $p=0.676$ & $p=0.0204^{*}$ & $p=0.672$ \\
\hline \multirow[t]{2}{*}{ Unmodified adiponectin (\%) } & - & $\rho=0.136$ & $\rho=0.393$ & $\rho=0.999$ & $\rho=0.404$ \\
\hline & - & $p=0.828$ & $p=0.512$ & $p<0.001^{*}$ & $p=0.500$ \\
\hline \multicolumn{6}{|l|}{ IRON OVERLOAD GROUP } \\
\hline \multirow[t]{2}{*}{ Total adiponectin } & $\rho=-0.245$ & $\rho=0.725$ & $\rho=-0.370$ & $\rho=0.927$ & $\rho=-0.266$ \\
\hline & $p=0.755$ & $p=0.275$ & $p=0.630$ & $p=0.0727$ & $p=0.734$ \\
\hline \multirow[t]{2}{*}{ Unmodified adiponectin (\%) } & - & $\rho=-0.485$ & $\rho=-0.607$ & $\rho=-0.432$ & $\rho=-0.623$ \\
\hline & - & $p=0.515$ & $p=0.393$ & $p=0.568$ & $p=0.377$ \\
\hline
\end{tabular}

Correlations between metabolic variables were evaluated within controls and iron overload cases. Significant correlations are indicated by "*" $p<0.05$.
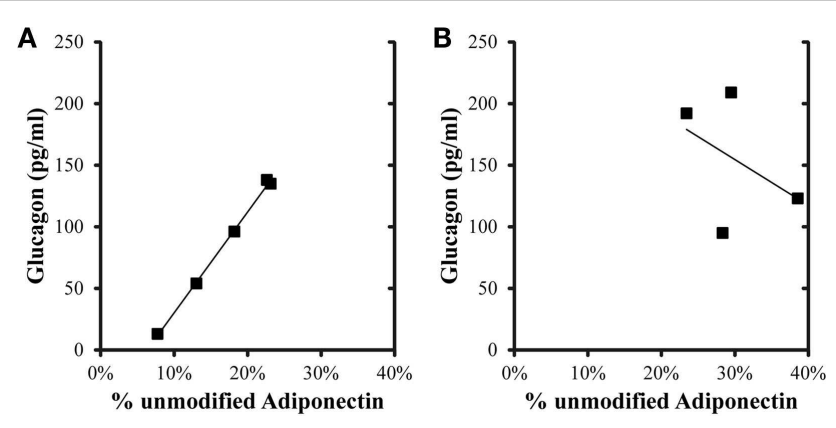

FIGURE 3 | Glucagon and percent unmodified adiponectin levels in the $\mathbf{2} \mathbf{h}$ post-prandial samples. The linear regression in (A) control group $(n=5)$ was $r=0.999, p<0.001$, and in the $(\mathbf{B})$ iron overload group $(n=4)$ was $r=0.432, p=0.568$.

humans with type 2 diabetes mellitus (47). Although oligomer formation is dependent on disulfide bond formation at Cys34 (34), lysine, and proline modifications within the collagenous domain are also required [reviewed in Ref. (33)]. For example, the level of HMW adiponectin is directly related to the extent of which the four conserved lysine residues are modified (17), while proline hydroxylation likely promotes rapid folding and thermostability, like that for other collagen-like domains (48). Further, published mutagenesis studies of four conserved adiponectin lysine residues demonstrated a shift in production from HMW to LMW multimers $(17,32)$. Together this suggests that the biological activity of adiponectin is directly related to the modification of key residues.

\section{POST-TRANSLATIONAL MODIFICATION AND RATIOMETRIC MEASUREMENT OF DOLPHIN ADIPONECTIN}

A search of tandem mass spectra from dolphin serum tryptic peptides was performed to determine whether known lysine and proline modifications were present on dolphin adiponectin. Glucosylgalactosyl modification of four lysines, Lys63, Lys66, Lys75, and Lys99 (Figure 1; Table 1), were identified which are conserved across mammals, though there was no evidence for glucosylgalactosyl modification of Lys31 reported for bovine adiponectin (31). There was also hydroxylation at proline residues Pro60, Pro93, and Pro96. The identification of hydroxylation at Pro60 (but not
Pro69) was supported by b- and y-ion series, although hydroxylation of the human equivalent of Pro69 (but not Pro60) has been described [human Pro71; (32)]. Overall, these results confirm dolphin adiponectin can be modified at key lysine and proline residues in the collagenous domain, though it is unclear exactly how the degree of modification affects oligomerization.

In this study, a new method to measure adiponectin was developed by measuring two quantotypic tryptic peptides, IFY and GDT, by PRM. To date, two other studies have used more than one peptide to quantify adiponectin by reaction monitoring. Homologs of IFY and GDT have been used to quantify human adiponectin (49), while more recently, GFPGIQGR as well as human IFY have been targeted for measurement (50). These peptides are located within the collagenous domain (GFPGIQGR and GDT) and globular domain (IFY; Figure 1). Using the human homologs of IFY and GDT as well as the same fragment ions as this study, Domanski et al. found IFY was threefold higher than GDT in a pooled sample of human plasma (49). Likewise IFY was on average fivefold higher than GDT in dolphin serum. Interestingly, the GDT homolog in humans contains an additional proline (human Pro86), and both prolines (human Pro86 and Pro 91) have been shown to be hydroxylated $(32,35)$. Because the GDT measurement was based on measuring the unmodified peptide, it would be affected by either proline hydroxylation. In the current study, oxidation of dolphin Pro89 was not identified. In addition to internal proline residues, GDT is surrounded by proline (32) and lysine (33) residues known to be modified. Modification of Lys75 is likely to prohibit cleavage by trypsin at this residue and therefore result in lower levels of GDT compared to IFY. This is also supported by the observation of two additional peptides with mis-cleavages after a modified Lys75 (Table 1). In the case of GFPGIQGR, it is expected that human Lys101 and Pro95 modifications may be limiting cleavage and measurement, respectively, resulting in the sixfold lower measurement of this unmodified peptide versus the GDT homolog in a pooled human plasma (50).

Since Lys75 modification is relevant to the multimerization of and formation of HMW adiponectin, percent unmodified adiponectin at Lys75 was determined using the ratio of GDT to IFY. The percent unmodified Lys75 adiponectin in the study population was between 8 and 39\%, suggesting that 61 to $92 \%$ of the adiponectin is modified at Lys75. The percentage of modified 
adiponectin is similar to levels of HMW adiponectin reported for humans [30-50\%; (51)], cats [50\%; (52)], and dogs [80\%; (43)]. For this reason the level of percent unmodified Lys75 appears to be a proxy of multimeric adiponectin, although further validation is necessary to determine the distribution of this modification across different multimers.

\section{COMPARISON OF TOTAL ADIPONECTIN LEVELS IN DOLPHINS WITH IRON OVERLOAD}

The hypothesis was tested that total adiponectin levels in dolphins with iron overload and putative insulin resistance have lower adiponectin levels compared to control dolphins. Serum levels were measured at two different states; fasting and $2 \mathrm{~h}$ postprandial, the later state being the one at which both insulin and glucagon were elevated in the animals with iron overload compared to control animals [see Ref. (3)]. To avoid misrepresentation, blood samples were not drawn on the same day, but rather at completely different subsequent periods of time as stated in the methods. There was no statistical difference between total adiponectin levels in dolphins with iron overload versus controls during fast or $2 \mathrm{~h}$ post-prandial; therefore this hypothesis was rejected. The absolute amount of modified adiponectin as a proxy of multimeric HMW adiponectin was calculated based on the unmodified Lys 75 peptide (i.e., GDT). There was no significant difference between iron overload cases and control dolphins regardless of fasting or feeding (data not shown). Although low total adiponectin levels have been reported in patients with non-alcoholic fatty liver disease (53) and inversely associated with serum ferritin and transferrin (54), total adiponectin does not appear to correspond to insulin resistance promoted by iron overload in dolphins.

Of note, the effect of gender and age on the level of adiponectin may be confounding in a small study population such as the one utilized in this study. In humans total adiponectin levels are higher in females than males, and increases with age in both sexes [reviewed by Brochu-Gaudreau et al. (55)]. Although the gender differences were not significantly different between both groups, females comprised $80 \%$ of the control group and $50 \%$ of the case group. Incongruent to that reported for other mammals, males tended to have higher total adiponectin levels and percent unmodified adiponectin than did females when dolphins were grouped by gender alone and classified by fasting or $2 \mathrm{~h}$ post-prandial. Based on this data, the group with the higher percentage of females (control) could have biased the result such that the hypothesis was less likely to have been accepted. Due to a limited number of animals available for study, caution should be taken when extrapolating interpretation of results to the population level, but also highlights the need for a future study with a larger frequency matched population.

\section{RATIOMETRIC MEASUREMENT OF ADIPONECTIN IN DOLPHINS WITH IRON OVERLOAD}

Because a reduction in the fraction of HMW adiponectin occurs in response to insulin or glucose administration in mice (56) and because the ratio of HMW to total adiponectin is correlated to improved hepatic insulin sensitivity (47), the fraction of unmodified Lys75 (i.e., GDT) adiponectin was measured in dolphins with iron overload and an insulin resistant phenotype. Although this assay has not yet been validated as a direct measure of multimeric forms of adiponectin (e.g., HMW adiponectin), the fact that lysine hydroxylation is correlated with adiponectin multimerization led us to speculate that the direct measurement of unmodified Lys75 (GDT) peptide relative to the total adiponectin peptide (IFY) could serve as a proxy for probable multimerization. If this assumption is valid, then the ratio of unmodified Lys75 peptide (GDT) to total adiponectin peptide (IFY) should be elevated in dolphins with iron overload at $2 \mathrm{~h}$ post-prandial because these animals have elevated insulin levels. During fasting, both groups of dolphins were essentially equivalent in the percent unmodified adiponectin; however, at $2 \mathrm{~h}$ post-prandial the percent of unmodified adiponectin was significantly higher in the iron overload cases (Figure 2). The elevation in $2 \mathrm{~h}$ post-prandial percent unmodified adiponectin in iron overload cases corresponds well to the fractional response of HMW adiponectin following oral glucose load or intraperitoneal insulin load in mice (56). The increase in percent unmodified Lys75 (GDT) peptide relative to the total adiponectin peptide (IFY) at the $2 \mathrm{~h}$ post-prandial time point also corresponded well with the elevated levels of insulin and glucagon reported by Venn-Watson et al. (3). These results support the assertion that GDT:IFY may serve as a proxy for HMW adiponectin multimers, but further studies are needed to confirm this speculation.

\section{CORRELATION OF ADIPONECTIN WITH GLUCAGON}

To further explore additional relationships between the total and ratiometric measurements of adiponectin, the Pearson product moment correlations between adiponectin measurements and select serum biochemistry values were calculated (Table 4). Interestingly, only glucagon levels correlated with the total and ratiometric measurements of adiponectin in the control group. When plotted against glucagon, the ratiometric measurement of adiponectin results in a nearly perfect linear relationship with glucagon levels in control dolphins; whereas, in dolphins with iron overload there was no correlation (Figure 3). The discriminatory value of this relationship as a classifier for metabolic insufficiency is very strong and could potentially be valuable as a marker of hepatic insulin improvement such as that reported for humans (47).

To the authors' knowledge, there are no previous studies describing such a relationship between glucagon and adiponectin in healthy mammals. A weak correlation between hepatic arterial adiponectin and glucagon was previously reported for patients with liver cirrhosis (57) and the authors speculated that the reason was because clearance routes were similar for both hormones; however, there was no correlation between total adiponectin and glucagon in dolphins with iron overload where hepatic dysfunction is more prevalent (2). It is possible that in healthy mammals, serum glucagon and adiponectin multimer concentrations are tightly controlled through mechanisms of clearance and that the correlation is lost in dolphins with hepatic dysfunction where glucagon is unable to be efficiently cleared and/or only higher molecular weight adiponectin is selectively cleared. In pigs, the clearance of glucagon largely occurs through elimination via the kidney and in dogs the fraction of glucagon extracted by the liver is only approximately $20 \%$ (58) suggesting that renal clearance, not hepatic clearance is the main sink. In this study there was 
no difference in eGFR between dolphin groups indicating that impaired renal clearance is an unlikely reason for preferential clearance of adiponectin forms. Adiponectin is cleared by both the liver and kidneys in mice with a half-life of about $75 \mathrm{~min}$ (59). However, adiponectin clearance does not appear to be as important as production in determining total serum adiponectin. In an obese, hyperinsulinemic mouse model $(o b / o b)$, circulating adiponectin levels are low despite the fact that clearance is reduced suggesting that adiponectin production is disproportionately depressed (59). Further, hyperinsulinemia is known to reduce the circulating amount of HMV adiponectin independent of clearance (19), which corresponds to the idea that impaired insulin-signaling is a major determinant of adiponectin level (33).

Another potential mechanism connecting both adiponectin and glucagon centers around the ability of fibroblast growth factor 21 (FGF21) to suppress glucagon (60) and stimulate adiponectin secretion (61). FGF21 is a primarily liver derived fasting hormone that has been shown to reduce HOMA-IR, triglyceride levels, and blood glucose in the $d b / d b$ mice when administered exogenously (62). Although speculative, the lack of correlation between glucagon and adiponectin in iron-overloaded dolphins might be partially explained by an inability to elevate FGF21 levels or a resistance to FGF21 signaling leading to improperly elevated glucagon levels and reduction in modified adiponectin. Because the link between FGF21, adiponectin, glucagon, and insulin resistance is very strong, future studies should consider measurements of FGF21 in dolphins. Taken together with the fact that insulin is a negative regulator of glucagon, and that dolphins with iron overload have significantly higher HOMA-IR scores, the evidence suggest that the higher ratio of GDT to IFY is most likely an effect of lower secretion of modified adiponectin coupled with improper glucagon feedback control.

\section{ADIPONECTIN AS AN ANTI-INFLAMMATORY}

Adiponectin is known to have other roles in addition to insulin sensitization one of which being as an anti-inflammatory mediator. Because there was no intergroup difference in ESR (Table 3), which is an indirect marker of inflammation, the correlation between systemic inflammation and circulating adiponectin in dolphins was not evident in this study. However, a hallmark feature of liver disease due to iron overload in dolphins is the accumulation of iron primarily in Kuppfer cells (macrophages) of the liver (2). The globular domain of adiponectin has been shown to elevate IL-10 and heme oxygenase 1 (HO-1), and reduce $\mathrm{TNF} \alpha$ expression in Kupffer cells stimulated with lipopolysaccharide $(63,64)$. Given that inactivation of Kupffer with gadolinium chloride prevents ethanol-induced fatty liver disease in rats (65), any reduction in the efficacy of adiponectin to promote IL-10 and reduce TNF $\alpha$ could promote the fatty liver phenotype afflicting dolphins with iron overload. Although the effect of extracellular iron has not been reported with regards to dynamics of adiponectin modification, high iron has been shown to reduce total adiponectin in adipocytes (8). If proper adiponectin modification is necessary to suppress inflammation due to activated Kupffer cells, then it is possible that the link between non-alcoholic fatty liver disease, hemochromatosis and percent unmodified adiponectin could underlie the metabolic disorders that ensue.

\section{FUTURE QUESTIONS AND CONCLUSION}

A number of basic questions remain unanswered with regards to adiponectin in dolphins. Based on a search of the dolphin genome, genes for adiponectin receptors R1, R2, and T-cadherin are present. Therefore, it is likely that homologous receptors for signaling exist in dolphins, but whether tissue receptor expression parallels human and rodent models and whether cell signal transduction pathways are conserved across species, remains to be established. Procollagen-lysine, 2-oxoglutarate 5-dioxygenase 3 (a.k.a. lysyl hydroxylase 3; Ensembl ID: ENSTTRG00000004781) is also present suggesting that differential enzyme activity responsible for lysine hydroxylation and subsequent glucosylgalactosylation of adiponectin in mice could underlie differences in the ratio of GDT to IFY (37). Whether or not adipocytes are the major source of adiponectin as in other mammals (33), remains to be determined.

In conclusion, an assay for adiponectin in dolphins has been established that relies on the highly specific measurement of tryptic peptides of adiponectin by PRM. Using this assay to study a small group of dolphins with iron overload has provided further insight into the hormonal dysregulation present in these animals. Moreover, these results highlight that a differential ratiometric measurement using two quantotypic peptides may serve as a marker of metabolic perturbations or improvement in dolphins. Future studies will address whether these peptide ratios can be used to determine the level of adiponectin modification and the relationship to degree of oligomerization. By defining a more precise adiponectin oligomer distribution along a continuum, more correlations with study endpoints could be evaluated. Because of the high sequence similarity between human and dolphin adiponectin and the presence of homologous gene products within both species, these findings may be directly applicable to the mechanistic understanding of both dolphin and human metabolism.

\section{AUTHORS CONTRIBUTION}

Benjamin A. Neely contributed to the development of the assay, to the experimental design, carried out analysis on the mass spectrometer, handled data processing, and drafted the manuscript. Kevin P. Carlin contributed to the experimental design, gathering sample data, data processing, and assisted in drafting the manuscript. John M. Arthur assisted in the interpretation of mass spectrometry data, critical analysis of the assay design, and drafting the manuscript. Wayne E. McFee procured the original serum sample for the development of the assay and assisted in the writing and review of the manuscript. Michael G. Janech conceived of the assay and study, contributed to the development of the assay, to the experimental design, and assisted in drafting the manuscript. All authors read and approved the final manuscript.

\section{ACKNOWLEDGMENTS}

The authors wish to acknowledge Dr. Stephanie Venn-Watson for her insightful discussions and facilitating the procurement of samples from her original study. The authors would also like to thank the animal care and training staff, interns, and veterinary technicians at the U.S. Navy Marine Mammal Program for their assistance with data and sample collection/processing. The Nephrology Proteomics Laboratory at MUSC was instrumental in the development of analytical techniques for this study. This study 
was supported by the Office of Naval Research Award Number N000141210294 and a ShEEP equipment grant from the Department of Veterans' Affairs. The bottlenose dolphin capture was performed under the National Oceanic and Atmospheric Administration's (NOAA) responsibility to respond to stranded, injured, and/or out-of-habitat marine mammals under the Marine Mammal Health and Stranding Response Act, 1992 (Title IV of Marine Mammal Protection Act). The authors also wish to acknowledge the National Marine Fisheries Service, South Carolina Marine Mammal Stranding Network, South Carolina Department of Natural Resources, U.S. Navy, and all the volunteers that assisted with the successful capture and release of the two bottlenose dolphins. This publication does not constitute an endorsement of any commercial product or intend to be an opinion beyond scientific or other results obtained by NOAA. No reference shall be made to NOAA, or this publication furnished by NOAA, to any advertising or sales promotion which would indicate or imply that NOAA recommends or endorses any proprietary product mentioned herein, or which has as its purpose an interest to cause the advertised product to be used or purchased because of this publication. The contents do not necessarily represent the views of the Department of Veterans Affairs or the United States Government.

\section{SUPPLEMENTARY MATERIAL}

The Supplementary Material for this article can be found online at http://www.frontiersin.org/Diabetes/10.3389/fendo.2013.00132/ abstract

Figure S1 | Fragmentation tables of three synthetic isotopically labeled target peptides along with observed fragment ions. Tables of fragment ion $\mathrm{m} / \mathrm{z}$ is shown for each peptide (generated using the Institute for Systems Biology online Fragment Ion Calculator; http://db.systemsbiology.net/ proteomicsToolkit/index.html). Observed fragment ions with highest peak intensities are labeled in MS/MS spectra, and colored red in tables.

Figure S2 | External calibration curves for yl3 $^{2+}$ from IFYNOQSHYDGTTGK. The solid line represents the $1 / x$ weighted linear regression, $R=0.99181$. Inset is provided to show performance at lower concentrations.

\section{REFERENCES}

1. Mazzaro LM, Johnson SP, Fair PA, Bossart G, Carlin KP, Jensen ED, et al. Iron indices in bottlenose dolphins (Tursiops truncatus). Comp Med (2012) 62:508-15.

2. Venn-Watson S, Benham C, Carlin K, DeRienzo D, St Leger J. Hemochromatosis and fatty liver disease: building evidence for insulin resistance in bottlenose dolphins (Tursiops truncatus). J Zoo Wildl Med (2012) 43:S35-47. doi:10.1638/2011-0146.1

3. Venn-Watson S, Carlin K, Ridgway S. Dolphins as animal models for type 2 diabetes: sustained, postprandial hyperglycemia and hyperinsulinemia. Gen Comp Endocrinol (2011) 170:193-9. doi:10.1016/j. ygcen.2010.10.005

4. Jehn M, Clark JM, Guallar E. Serum ferritin and risk of the metabolic syndrome in U.S. adults.

Figure S3 | External calibration curves for $\mathbf{y l 4}^{2+}$ from IFYNOQSHYDGTTGK. The solid line represents the $1 / x$ weighted linear regression, $R=0.98945$. Inset is provided to show performance at lower concentrations.

Figure S4 | External calibration curves for yl2 ${ }^{2+}$ from IFYNQQSHYDGTTGK The solid line represents the $1 / x$ weighted linear regression, $R=0.99056$. Inset is provided to show performance at lower concentrations.

Figure S5 | External calibration curves for y7 from GDTGETGVTGVEGPR. The solid line represents the $1 / x$ weighted linear regression, $R=0.99278$. Inset is provided to show performance at lower concentrations.

Figure S6 | External calibration curves for y9 from GDTGETGVTGVEGPR. The solid line represents the $1 / x$ weighted linear regression, $R=0.9873$. Inset is provided to show performance at lower concentrations.

Figure S7 | External calibration curves for yl0 from GDTGETGVTGVEGPR The solid line represents the $1 / x$ weighted linear regression, $R=0.98691$. Inset is provided to show performance at lower concentrations.

Table S1 | lon pairs and instrument parameters used for PRM. Each endogenous target peptide had an isotopically labeled synthetic version constructed with either a C-terminal 8Lys or 10Arg, designated by a "^" and referred to as heavy. Fragment ion peak areas were extracted from each MS/MS experiment using these monoisotopic masses $\pm 0.05 \mathrm{~m} / \mathrm{z}$

Table S2 | Complete hematologic and serum biochemistry data of study group. A Wilcoxon rank-sum test was used to compare blood chemistry values between groups.

Table S3 | Assay performance measures. To evaluate assay performance on the days of analysis, experimental triplicates were used quantify assay variability and detection limits. The average peak area ratio was determined based on all samples analyzed.

Table S4 | Measured adiponectin concentrations in blood from different organisms using different techniques. Reported adiponectin measurements by ELISA are typically microgram per milliliter therefore concentrations were converted using the molecular weight of adiponectin from each species (an elephant seal was assumed to be exactly $26 \mathrm{kDa}$ ).

8. Gabrielsen JS, Gao Y, Simcox JA, Huang J, Thorup D, Jones D, et al. Adipocyte iron regulates adiponectin and insulin sensitivity. J Clin Invest (2012) 122:3529-40. doi:10.1172/JCI44421

9. Viscarra JA, Champagne CD, Crocker DE, Ortiz RM. 5'AMP-activated protein kinase activity is increased in adipose tissue of northern elephant seal pups during prolonged fastinginduced insulin resistance. $J$ Endocrinol (2011) 209:317-25. doi:10.1530/JOE-11-0017

10. Viscarra JA, Vazquez-Medina JP, Crocker DE, Ortiz RM. Glut4 is upregulated despite decreased insulin signaling during prolonged fasting in northern elephant seal pups. Am J Physiol Regul Integr Comp Physiol (2011) 300:R150-4. doi:10.1152/ajpregu.00478.2010

11. Ishioka K, Omachi A, Sagawa M, Shibata H, Honjoh T, Kimura K, et al. Canine adiponectin: cDNA structure, mRNA expression in adipose tissues and reduced plasma levels in obesity. Res Vet Sci (2006) 80:127-32. doi:10.1016/j.rvsc.2005. 05.011

12. Brunson BL, Zhong Q, Clarke KJ, Bedi D, Braden TD, van Santen E, et al. Serum concentrations of adiponectin and characterization of adiponectin protein complexes in dogs. Am J Vet Res (2007) 68:57-62. doi:10.2460/ajvr.68.1.57

13. Tvarijonaviciute A, MartinezSubiela S, Ceron JJ. Validation of 2 commercially available enzymelinked immunosorbent assays for adiponectin determination in canine serum samples. Can J Vet Res (2010) 74:279-85.

14. Holman SW, Sims PF, Eyers CE. The use of selected reaction monitoring in quantitative proteomics. Bioanalysis (2012) 4:1763-86. doi:10. 4155/BIO.12.126 
15. Picotti P, Aebersold R. Selected reaction monitoring-based proteomics: workflows, potential, pitfalls and future directions. Nat Methods (2012) 9:555-66. doi:10. 1038/nmeth.2015

16. Peterson AC, Russell JD, Bailey DJ, Westphall MS, Coon JJ. Parallel reaction monitoring for high resolution and high mass accuracy quantitative, targeted proteomics. Mol Cell Proteomics (2012) 11:1475-88. doi:10.1074/mcp.O112.020131

17. Wang Y, Lam KS, Chan L, Chan KW, Lam JB, Lam MC, et al. Post-translational modifications of the four conserved lysine residues within the collagenous domain of adiponectin are required for the formation of its high molecular weight oligomeric complex. J Biol Chem (2006) 281:16391-400. doi: 10.1074/jbc.M513907200

18. Hara K, Horikoshi M, Yamauchi T, Yago H, Miyazaki O, Ebinuma $\mathrm{H}$, et al. Measurement of the high-molecular weight form of adiponectin in plasma is useful for the prediction of insulin resistance and metabolic syndrome. Diabetes Care (2006) 29:1357-62. doi:10. 2337/dc05-1801

19. Basu R, Pajvani UB, Rizza RA, Scherer PE. Selective downregulation of the high molecular weight form of adiponectin in hyperinsulinemia and in type 2 diabetes: differential regulation from nondiabetic subjects. Diabetes (2007) 56:2174-7. doi:10.2337/db07-0185

20. Venn-Watson S, Smith CR, Jensen ED. Assessment of increased serum aminotransferases in a managed Atlantic bottlenose dolphin (Tursiops truncatus) population. J Wildl Dis (2008) 44:318-30.

21. Johnson SP, Venn-Watson SK, Cassle SE, Smith CR, Jensen ED, Ridgway SH. Use of phlebotomy treatment in Atlantic bottlenose dolphins with iron overload. $J$ Am Vet Med Assoc (2009) 235:194-200. doi:10.2460/javma.235.2.194

22. Venn-Watson S, Jensen ED, Ridgway $\mathrm{SH}$. Effects of age and sex on clinicopathologic reference ranges in a healthy managed Atlantic bottlenose dolphin population. J Am Vet Med Assoc (2007) 231:596-601. doi:10.2460/javma.231.4.596

23. King-Brink M, Sebranek JG. Combustion method for determination of crude protein in meat and meat products: collaborative study. J AOAC Int (1993) 76:787-93.

24. Matthews DR, Hosker JP, Rudenski AS, Naylor BA, Treacher DF,
Turner RC. Homeostasis model assessment: insulin resistance and beta-cell function from fasting plasma glucose and insulin concentrations in man. Diabetologia (1985) 28:412-9. doi:10.1007/ BF00280883

25. Venn-Watson S, Smith CR, Dold C, Ridgway SH. Use of a serum-based glomerular filtration rate prediction equation to assess renal function by age, sex, fasting, and health status in bottlenose dolphins (Tursiops truncatus). Mar Mamm Sci (2008) 24:71-80. doi:10.1111/j.1748-7692. 2007.00162.x

26. Kuzyk MA, Smith D, Yang J, Cross TJ, Jackson AM, Hardie DB, et al. Multiple reaction monitoringbased, multiplexed, absolute quantitation of 45 proteins in human plasma. Mol Cell Proteomics (2009) 8:1860-77. doi:10.1074/ mcp.M800540-MCP200

27. Lindblad-Toh K, Garber M, Zuk O, Lin MF, Parker BJ, Washietl S, et al. A high-resolution map of human evolutionary constraint using 29 mammals. Nature (2011) 478:476-82. doi:10.1038/nature10530

28. Vizcaino JA, Cote RG, Csordas A, Dianes JA, Fabregat A, Foster JM, et al. The proteomics identifications (PRIDE) database and associated tools: status in 2013. Nucleic Acids Res (2013) 41:D1063-9. doi: 10.1093/nar/gks1262

29. Long GL, Winefordner JD. Limit of detection. A closer look at the IUPAC definition. Anal Chem (1983) 55:712A-24A. doi:10.1021/ ac00258a001

30. Wang Y, Xu A, Knight C, Xu LY, Cooper GJ. Hydroxylation and glycosylation of the four conserved lysine residues in the collagenous domain of adiponectin. Potential role in the modulation of its insulinsensitizing activity. J Biol Chem (2002) 277:19521-9.

31. Wang Y, Lu G, Wong WP, Vliegenthart JF, Gerwig GJ, Lam KS, et al. Proteomic and functional characterization of endogenous adiponectin purified from fetal bovine serum. Proteomics (2004) 4:3933-42. doi:10.1002/pmic. 200400826

32. Richards AA, Stephens T, Charlton HK, Jones A, Macdonald GA, Prins JB, et al. Adiponectin multimerization is dependent on conserved lysines in the collagenous domain: evidence for regulation of multimerization by alterations in posttranslational modifications. Mol Endocrinol (2006) 20:1673-87. doi:10.1210/me.2005-0390
33. Wang Y, Lam KS, Yau MH, Xu A. Post-translational modifications of adiponectin: mechanisms and functional implications. Biochem J (2008) 409:623-33. doi:10.1042/ BJ20071492

34. Frizzell N, Rajesh M, Jepson MJ, Nagai R, Carson JA, Thorpe SR, et al. Succination of thiol groups in adipose tissue proteins in diabetes: succination inhibits polymerization and secretion of adiponectin. $J$ Biol Chem (2009) 284:25772-81. doi:10. 1074/jbc.M109.019257

35. Richards AA, Colgrave ML, Zhang J, Webster J, Simpson F, Preston E, et al. Sialic acid modification of adiponectin is not required for multimerization or secretion but determines half-life in circulation. $\mathrm{Mol}$ Endocrinol (2010) 24:229-39. doi: 10.1210/me.2009-0133

36. Simpson F, Whitehead JP. Adiponectin - it's all about the modifications. Int $J$ Biochem Cell Biol (2010) 42:785-8. doi:10.1016/j.biocel.2009.12.021

37. Ruotsalainen $\mathrm{H}$, Risteli M, Wang $\mathrm{C}$, Wang Y, Karppinen M, Bergmann $\mathrm{U}$, et al. The activities of lysyl hydroxylase 3 (LH3) regulate the amount and oligomerization status of adiponectin. PLoS One (2012) 7:e50045. doi:10.1371/journal.pone.0050045

38. Lin S, Shaler TA, Becker $\mathrm{CH}$. Quantification of intermediateabundance proteins in serum by multiple reaction monitoring mass spectrometry in a single-quadrupole ion trap. Anal Chem (2006) 78:5762-7. doi:10.1021/ac060613f

39. Domanski D, Smith DS, Miller CA, Yang Y, Jackson AM, Cohen Freue $G$, et al. High-flow multiplexed MRM-based analysis of proteins in human plasma without depletion or enrichment. Clin Lab Med (2011) 31:371-84. doi:10.1016/j.cll. 2011.07.005

40. Shi T, Fillmore TL, Sun X, Zhao R, Schepmoes AA, Hossain $M$, et al. Antibody-free, targeted mass-spectrometric approach for quantification of proteins at low picogram per milliliter levels in human plasma/serum. Proc Natl Acad Sci U S A (2012) 109:15395-400. doi:10.1073/pnas. 1204366109

41. Rasmussen-Torvik LJ, Wassel CL, Ding J, Carr J, Cushman M, Jenny $\mathrm{N}$, et al. Associations of body mass index and insulin resistance with leptin, adiponectin, and the leptinto-adiponectin ratio across ethnic groups: the Multi-Ethnic Study of
Atherosclerosis (MESA). Ann Epidemiol (2012) 22:705-9. doi:10. 1016/j.annepidem.2012.07.011

42. Kobayashi M, Ohno T, Kawada T, Ikegami H, Nishimura M, Horio F. Serum adiponectin concentration: its correlation with diabetes-related traits and quantitative trait loci analysis in mouse SMXA recombinant inbred strains. Biosci Biotechnol Biochem (2006) 70:677-83. doi: 10.1271/bbb.70.677

43. Verkest KR, Rand JS, Fleeman LM, Morton JM, Richards AA, Rose FJ, et al. Distinct adiponectin profiles might contribute to differences in susceptibility to type 2 diabetes in dogs and humans. Domest Anim Endocrinol (2011) 41:67-73. domaniend.2011.03.003

44. Mielenz M, Mielenz B, Singh SP, Kopp C, Heinz J, Haussler S, et al. Development, validation, and pilot application of a semiquantitative Western blot analysis and an ELISA for bovine adiponectin. Domest Anim Endocrinol (2013) 44(3):121-30. doi:10.1016/j. domaniend.2012.10.004

45. Berg AH, Combs TP, Du X, Brownlee M, Scherer PE. The adipocytesecreted protein Acrp30 enhances hepatic insulin action. Nat Med (2001) 7:947-53. doi:10.1038/90992

46. Fruebis J, Tsao TS, Javorschi S, Ebbets-Reed D, Erickson MR, Yen FT, et al. Proteolytic cleavage product of $30-\mathrm{kDa}$ adipocyte complement-related protein increases fatty acid oxidation in muscle and causes weight loss in mice. Proc Natl Acad Sci U S A (2001) 98:2005-10. doi:10.1073/pnas.98.4.2005

47. Pajvani UB, Hawkins $M$, Combs TP, Rajala MW, Doebber T, Berger JP, et al. Complex distribution, not absolute amount of adiponectin, correlates with thiazolidinedione-mediated improvement in insulin sensitivity. J Biol Chem (2004) 279:12152-62. doi:10.1074/jbc.M311113200

48. Chopra RK, Ananthanarayanan VS. Conformational implications of enzymatic proline hydroxylation in collagen. Proc Natl Acad Sci U S A (1982) 79:7180-4. doi:10.1073/ pnas.79.23.7180

49. Domanski D, Percy AJ, Yang J, Chambers AG, Hill JS, Freue $\mathrm{GV}$, et al. MRM-based multiplexed quantitation of 67 putative cardiovascular disease biomarkers in human plasma. Proteomics (2012) 12:1222-43. doi:10. 1002/pmic. 201100568 
50. Percy AJ, Chambers AG, Yang J, Hardie DB, Borchers CH. Advances in multiplexed MRM-based protein biomarker quantitation toward clinical utility. Biochim Biophys Acta (2013). doi:10.1016/j.bbapap.2013. 06.008

51. Caselli C, Melaiu O, Maltinti M, Del Ry S, Cabiati M, Prescimone $\mathrm{T}$, et al. A methodological reappraisal of total and high molecular weight adiponectin determination in human peripheral circulation: comparison of four immunometric assays. Clin Chem Lab Med (2010) 48:561-8. doi:10.1515/CCLM.2010. 104

52. Tan HY, Rand JS, Morton JM, Fleeman LM, Armstrong PJ, Coradini $\mathrm{M}$, et al. Adiponectin profiles are affected by chronic and acute changes in carbohydrate intake in healthy cats. Gen Comp Endocrinol (2011) 172:468-74. doi:10.1016/j. ygcen.2011.04.012

53. Bianchi G, Bugianesi E, Frystyk J, Tarnow L, Flyvbjerg A, Marchesini G. Adiponectin isoforms, insulin resistance and liver histology in nonalcoholic fatty liver disease. Dig Liver Dis (2011) 43:73-7. doi:10. 1016/j.dld.2010.05.011

54. Wlazlo N, van Greevenbroek MM, Ferreira I, Jansen EH, Feskens EJ, van der Kallen CJ, et al. Iron metabolism is associated with adipocyte insulin resistance and plasma adiponectin: the Cohort on Diabetes and Atherosclerosis Maastricht (CODAM) study. Diabetes Care (2013) 36:309-15. doi:10. 2337/dc12-0505

55. Brochu-Gaudreau K, Rehfeldt C, Blouin R, Bordignon V, Murphy BD, Palin MF. Adiponectin action from head to toe. Endocrine (2010) 37:11-32. doi:10.1007/s12020-0099278-8

56. Pajvani UB, Du X, Combs TP Berg AH, Rajala MW, Schulthess $\mathrm{T}$, et al. Structure-function studies of the adipocyte-secreted hormone Acrp30/adiponectin. J Biol Chem (2003) 278:9073-85. doi:10. 1074/jbc.M207198200

57. Tietge UJ, Boker KH, Manns MP, Bahr MJ. Elevated circulating adiponectin levels in liver cirrhosis are associated with reduced liver function and altered hepatic hemodynamics. Am J Physiol Endocrinol Metab (2004) 287:E82-9. doi:10. 1152/ajpendo.00494.2003

58. Herold KC, Jaspan JB. Hepatic glucagon clearance during insulin induced hypoglycemia. Horm Metab Res (1986) 18:431-5. doi:10.1055/s-2007-1012339

59. Halberg N, Schraw TD, Wang ZV, Kim JY, Yi J, Hamilton MP, et al. Systemic fate of the adipocytederived factor adiponectin. Diabetes (2009) 58:1961-70. doi:10. 2337/db08-1750

60. Kharitonenkov A, Shiyanova TL, Koester A, Ford AM, Micanovic R,
Galbreath EJ, et al. FGF-21 as a novel metabolic regulator. J Clin Invest (2005) 115:1627-35. doi:10. 1172/JCI23606

61. Holland WL, Adams AC, Brozinick JT, Bui HH, Miyauchi Y, Kusminski CM, et al. An FGF21adiponectin-ceramide axis controls energy expenditure and insulin action in mice. Cell Metab (2013) 17:790-7. doi:10.1016/j.cmet.2013. 03.019

62. Kim HW, Lee JE, Cha JJ, Hyun YY, Kim JE, Lee MH, et al. Fibroblast growth factor 21 improves insulin resistance and ameliorates renal injury in $d b / d b$ mice. Endocrinology (2013) 154:3366-76. doi:10.1210/ en.2012-2276

63. Huang H, Park PH, McMullen MR, Nagy LE. Mechanisms for the anti-inflammatory effects of adiponectin in macrophages. J Gas troenterol Hepatol (2008) 23(Suppl 1):S50-3. doi:10.1111/j.1440- 1746 . 2007.05284.x

64. Mandal P, Park PH, McMullen MR, Pratt BT, Nagy LE. The antiinflammatory effects of adiponectin are mediated via a heme oxygenase-1-dependent pathway in rat Kupffer cells. Hepatology (2010) 51:1420-9. doi:10.1002/hep.23427

65. Adachi Y, Bradford BU, Gao W, Bojes HK, Thurman RG. Inactivation of Kupffer cells prevents early alcohol-induced liver injury.
Hepatology (1994) 20:453-60. doi: 10.1002/hep.1840200227

Conflict of Interest Statement: The authors declare that the research was conducted in the absence of any commercial or financial relationships that could be construed as a potential conflict of interest.

Received: 08 August 2013; paper pending published: 16 August 2013; accepted: 05 September 2013; published online: 20 September 2013.

Citation: Neely BA, Carlin KP, Arthur $J M$, McFee WE and Janech MG (2013) Ratiometric measurements of adiponectin by mass spectrometry in bottlenose dolphins (Tursiops truncatus) with iron overload reveal an association with insulin resistance and glucagon. Front. Endocrinol. 4:132. doi: 10.3389/fendo.2013.00132

This article was submitted to Diabetes, a section of the journal Frontiers in Endocrinology.

Copyright $(2013$ Neely, Carlin, Arthur, McFee and Janech. This is an open-access article distributed under the terms of the Creative Commons Attribution License (CC BY). The use, distribution or reproduction in other forums is permitted, provided the original author(s) or licensor are credited and that the original publication in this journal is cited, in accordance with accepted academic practice. No use, distribution or reproduction is permitted which does not comply with these terms. 